\title{
Estimation of groin recurrence risk in patients with squamous cell vulvar carcinoma by the assessment of marker gene expression in the lymph nodes
}

\author{
Magdalena Kowalewska ${ }^{1 *}$, Jakub Radziszewski ${ }^{2}$, Krzysztof Goryca $^{3,4}$, Mateusz Bujko', \\ Malgorzata Oczko-Wojciechowska ${ }^{5}$, Michal Jarzab ${ }^{5}$, Janusz Aleksander Siedlecki ${ }^{1}$ and Mariusz Bidzinski ${ }^{6}$
}

\begin{abstract}
Background: Regional lymph node (LN) status is a well-known prognostic factor for vulvar carcinoma (VC) patients. Although the reliable LN assessment in VC is crucial, it presents significant diagnostic problems. We aimed to identify specific mRNA markers of $V C$ dissemination in the $L N$ and to address the feasibility of predicting the risk of nodal recurrence by the patterns of gene expression.

Methods: Sentinel and inguinal LN samples from 20 patients who had undergone surgery for stage $T_{1-3,}, N_{0-2,}, M_{0}$ primary vulvar squamous cell carcinoma were analyzed. Gene expression profiles were assessed in four metastatic $[\mathrm{LN}(+)]$ and four histologically negative $[\mathrm{LN}(-)]$ lymph node samples obtained from four VC patients, by the Affymetrix U133 Plus 2.0 gene expression microarrays. Of the set of genes of the highest expression in the metastatic LNs compared to LN(-), seven candidate marker genes were selected: PERP, S100A8, FABP5, SFN, CA12, JUP and CSTA, and the expression levels of these genes were further analyzed by the real-time reverse transcription polymerase chain reaction (qRT-PCR) in $71 \mathrm{LN}$ samples.
\end{abstract}

Results: All of the seven genes in question were significantly increased in $L N(+)$ compared to $L N(-)$ samples. In the initial validation of the seven putative markers of metastatic $L N$, the Cox proportional hazard model pointed to SFN, CA12 and JUP expression to significantly relate to the time to groin recurrence in VC patients.

Conclusions: Our findings first provided evidence that SFN, CA12 and JUP have a potential of marker genes for the prediction of the groin recurrence LN in VC patients.

Keywords: Vulvar carcinoma, Lymph node, Microarray, Expression marker, Real-time RT-PCR

\section{Background}

Vulvar carcinoma (VC) is a rare genital malignancy with age-standardized incidence rates (ASR) ranging worldwide between 0.5 and 1.5 per 100,000 [1]. The current ASR in Poland is 1.0, and 436 new cases of VC were diagnosed and 232 VC-related deaths were recorded in 2009 (age-standardized mortality rate 0.5) [2]. Squamous cell carcinoma is the most common histological type of $\mathrm{VC}$, representing approximately $90 \%$ of lesions. VC

\footnotetext{
*Correspondence: magdak@coi.waw.pl

'Department of Molecular Biology, Maria Sklodowska-Curie Memorial Cancer Centre and Institute of Oncology, Roentgena, 5, Warsaw 02-781, Poland Full list of author information is available at the end of the article
}

spreads primarily by the local expansion and via the lymphatic system.

Lymph node (LN) status is the most important prognostic factor in VC patients [3]. Up to $24 \%$ of patients with LNs clinically considered to be normal have metastases, while more than $20 \%$ of patients with enlarged nodes in clinical examination are found metastases-free in the histopathologic assessment [4]. Therefore, in many centres the VC staging comprises an ultrasound-guided fine-needle biopsy of the suspicious groin LNs and cytologic evaluation of the regional LN status. In early stage VC patients, the probability of a positive inguinal LN finding is only $11-25 \%$ [5]. This means that if all women with early VC

\section{Biomed Central}

(c) 2012 Kowalewska et al.; licensee BioMed Central Ltd. This is an Open Access article distributed under the terms of the Creative Commons Attribution License (http://creativecommons.org/licenses/by/2.0), which permits unrestricted use, distribution, and reproduction in any medium, provided the original work is properly cited. 
were assigned to lymphadenectomy, approximately $80 \%$ of them would undergo overtreatment. At present, the concept of sentinel LN biopsy in early stage VC is becoming increasingly accepted while the problem of optimal treatment of patients with metastatic regional LNs is still being discussed. Another issue is the assessment of the risk of metastases in non-sentinel LNs after removal of all positive sentinel LNs.

Finding a method of an accurate and sensitive pre- or perioperative determination of pathologic status of groin nodes would be of a great value to aid therapeutic decisions in early stages of VC. Time-consuming, routine pathological evaluation of hematoxylin- and eosin-stained (H\&E) LN sections lacks sensitivity. Therefore, a real-time reverse-transcription PCR (qRT-PCR) is being used in various tumours to determine the presence of metastatic cells in LNs [6,7]. However, before the qRT-PCR-based molecular staging of VC can be applied, clinically relevant markers [8] need to be identified. In this study, to identify specific mRNA markers of VC dissemination into LNs, expression microarrays were employed.

\section{Materials}

The material was obtained from 20 patients treated for vulvar carcinoma in the Maria Sklodowska-Curie Memorial Cancer Centre and Institute of Oncology in Warsaw between March 2003 and September 2006. Patients with microscopically confirmed vulvar squamous cell carcinoma in clinical stage $\mathrm{T}_{1-3}, \mathrm{~N}_{0-2}, \mathrm{M}_{0}$ and with no prior treatment for this or any other malignancy were enrolled. The selected characteristics, including the TNM categories according to the AJCC (American Joint Committee on Cancer TNM staging system), of VC patients are presented in Table 1. Surgery and LN identification were performed as described previously [9]. The median LN count was 5 nodes in the right groin, range $2-13$, while in the left groin the median LN count was 5.5 nodes, range 0-15. The study was approved by the Independent Ethics Committee of the Maria Sklodowska-Curie Memorial Cancer Centre and Institute of Oncology in Warsaw and all patients gave their informed consent. LN specimens were divided into two parts: one part was examined histologically as described previously [10], the other was frozen in liquid nitrogen immediately after collection and stored at $-70^{\circ} \mathrm{C}$ until RNA isolation. Median follow-up time, determined from the date of surgery to the date of death or the date of the last interview, was 1.2 years (range $0.43-6.29$ ).

Microarray analysis of gene expression profiles was performed in four pairs of LN samples from four VC patients. One metastatic $\mathrm{LN}[\mathrm{LN}(+)]$ and one histologically negative $[\mathrm{LN}(-)]$, according to a routine pathological examination

Table 1 Individual patient data

\begin{tabular}{|c|c|c|c|c|c|c|}
\hline Patient No. & Age (years) & TNM Stage & Histological Grade & Histological subtype & HPV Status/Type & Groin recurrence \\
\hline 5 & 59.3 & T2NOMO & n.d. & $\mathrm{K}$ & n.d. & occurred \\
\hline 7 & 81.3 & T2N1M0 & G2 & K & n.d. & occurred \\
\hline 8 & 61.0 & T2N1M0 & G2 & K & n.d. & occurred \\
\hline $15^{*}$ & 77.2 & T2N2M0 & G2 & K & negative & occurred \\
\hline 18 & 78.3 & T3N2M0 & G1 & $\mathrm{nK}$ & negative & not observed \\
\hline 19 & 51.1 & T2N1M0 & G3 & $\mathrm{nK}$ & negative & not observed \\
\hline $21^{*}$ & 93.9 & T2N1M0 & G2 & K & negative & not observed \\
\hline 23 & 71.5 & T2N1M0 & G2 & K & negative & not observed \\
\hline 25 & 75.3 & T2NOMO & G1 & K & negative & not observed \\
\hline 26 & 56.8 & T2NOMO & G1 & K & negative & not observed \\
\hline 30 & 45.3 & $\mathrm{~T}_{2} \mathrm{NOMO}^{* *}$ & G3 & $\mathrm{nK}$ & HPV16 & not observed \\
\hline 34 & 71.2 & T2N1M0 & G2 & $\mathrm{nK}$ & negative & not observed \\
\hline 41 & 80.6 & T2N1M0 & G1 & K & negative & occurred \\
\hline 45 & 76.1 & T2NOMO & G3 & nK & negative & not observed \\
\hline $46^{*}$ & 64.5 & T2N1M0 & G3 & K & negative & occurred \\
\hline 49 & 76.0 & T2NOMO & G3 & $\mathrm{nK}$ & negative & occurred \\
\hline 51 & 56.7 & $\mathrm{~T} 2 \mathrm{~N} 2 \mathrm{MO}$ & G3 & K & negative & occurred \\
\hline 53 & 70.3 & T2NOMO** & G2 & K & negative & occurred \\
\hline 58 & 52.4 & T1bN2M0 & G2 & K & negative & not observed \\
\hline $61^{*}$ & 76.6 & T2N1M0 & G2 & $\mathrm{nK}$ & negative & not observed \\
\hline
\end{tabular}

Abbreviations: $K$ - keratinising squamous cell carcinoma; $n K$ - non-keratinising squamous cell carcinoma; $n . d$. - not determined; ${ }^{*}-L N s$ of these patients were incorporated into microarray analysis, ${ }^{* *}$ - patients subjected to the unilateral lymphadenectomy. 
with $H \& E$, was examined per each of the four patients. These patients had human papillomavirus (HPV)-negative tumours, as previously determined using the Linear Array HPV Detection Kit and Linear Array HPV Genotyping Test (Roche Molecular Systems, Inc) [10].

A total of 71 right and left LNs (sentinel and inguinal specimens), from $20 \mathrm{VC}$ patients were included in the real-time RT-PCR analysis of expression of selected genes. In a routine pathological examination, 22 LNs were evaluated as $\mathrm{LN}(+)$ and the remaining 49 were histologically negative $[\mathrm{LN}(-)]$.

\section{Methods}

\section{RNA isolation}

Total RNA was isolated from approximately $200 \mathrm{mg}$ of pulverised (with the Microdismembrator II, B Braun Biotech International) LN samples using Nucleospin RNA L kit (Macherey-Nagel), according to the manufacturer's protocol. RNA quality was assessed using the Agilent 2100 Bioanalyzer and RNA 6000 Nano Chip Kit (Agilent Technologies).

\section{Microarray procedure}

cDNA synthesis was carried out from $5 \mu \mathrm{g}$ of RNA with the One-Cycle cDNA Synthesis Kit (Affymetrix). After purification (GeneChip Ample Cleanup Module), $7 \mu$ of double-stranded cDNA were used for biotinylated cRNA synthesis with IVT Labeling Kit (Affymetrix). The quantity and quality of the obtained cRNA were assessed using the Agilent 2100 Bioanalyser and RNA 6000 Nano Chip Kit (Agilent Technologies). Labeled cRNA was purified using a GeneChip Sample Cleanup Module, fragmented and hybridized with the Affymetrix GeneChip Human Genome U133 Plus 2.0 arrays. Washing, staining with streptavidin-phycoerythrin conjugate and scanning of the arrays in the Affymetrix GeneChip 3000 scanner were performed as recommended by the Affymetrix Gene Expression Analysis Technical Manual.

\section{Microarray data analysis}

All the arrays were normalized by the GCRMA algorithm using a Bioconductor [11] (version 2.8.1) package gcrma version 2.14.1. The expression levels were $\log _{2}$ transformed. We filtered out all the probe sets with signal level below 7.5 in at least 8 samples. Genes differentially expressed in involved $[\mathrm{LN}(+)]$ and uninvolved $[\mathrm{LN}(-)]$ lymph nodes were searched by a random-variance t-test, with the statistical significance threshold set at $P<0.01$. To reduce false-differential gene expression, a Benjamini-Hochberg [12] multiple testing correction was applied. The full dataset has been deposited in the Gene Expression Omnibus repository (accession no GSE28442).
The probe sets with differential expression in two samples - one $\mathrm{LN}(+)$ and one $\mathrm{LN}(-)$ - obtained from patient No 15 were chosen to be analyzed first with pumaDE function from PUMA package version 1.8.1 [13]. Differentially expressed probe sets were annotated with Gene Ontology (GO) terms (GO.db version 2.2.5) using the Bioconductor [11] packages GOstats (version 2.8.0) and package annotate (version 1.20.1). The significance of differential representation of GO terms between the specified lists of probe sets was determined by the hypergeometric test implemented in GOstats (version 2.8.0). $P$ values returned by GOstats were corrected for testing of multiple hypotheses with the Benjamini-Hochberg method implemented in an $\mathrm{R}$ environment (version 2.8.1, The $\mathrm{R}$ Foundation for Statistical Computing; http://www.r-project.org). Adjusted $P$ values of less than 0.05 were considered significant. The same procedure was applied to the three additional pairs of $\mathrm{LN}(+)$ and $\mathrm{LN}(-)$ samples from three patients (No. 21, 46 and 61).

This analysis has provided a set of candidate marker genes, which were further investigated to define their tumour specificity using Genevestigator V3, a web-based microarray database and analysis system [14].

\section{Real time RT-PCR}

RNA was extracted from $71 \mathrm{LN}$ samples and $1 \mu \mathrm{g}$ from each sample was reverse-transcribed by using the $\mathrm{RT}^{2}$ First Strand Kit (C-03) from SA Biosciences. Custom PCR arrays (SA Biosciences) were used to simultaneously examine the mRNA levels of seven genes of interest according to the manufacturer's protocol.

The arrays also included primers for two housekeeping genes and three internal controls. Quantitative real-time PCR analysis was performed with the RT2 Real-Time PCR Master Mix (SA Biosciences) in the 7500 Fast RealTime PCR System (Applied Biosystems), according to the manufacturer's instructions (SA Biosciences). The collected data were analyzed using threshold-cycle $(\mathrm{Ct})$ values for the genes with the SDS 2.1 software (Applied Biosystems). Normalization was performed based on the mean values of two housekeeping genes, $H M B S$ and $H S P 90 A B 1$, and the relative amounts of RNA for each gene were calculated by the $2^{-\Delta C T}$ method using DataAssist ${ }^{\mathrm{Tu}}$ Software (Applied Biosystems). Expression levels for each gene were visualized using GraphPadPrism (La Jolla, CA, USA).

\section{Statistical analysis}

The significance of difference between the selected gene expression level in each of $\mathrm{LN}(+)$ and $\mathrm{LN}(-)$ samples was assessed by using Wilcoxon test. $P<0.01$ was considered significant.

The Cox proportional-hazard model with Bonferroni correction for multiple hypotheses testing was applied to 
estimate the effect of gene expression levels in LN samples on the time to groin recurrence (TTR). The highest expression value of a given gene of all obtained in different LN samples of the same patient was chosen to be included in the statistical analysis. TTR was calculated from the date of primary surgery to the date of groin recurrence. MedCalc (Mariakerke, Belgium) software was used to generate Kaplan-Meier curves and to compare TTR using two sided log-rank analysis. The median of maximum gene expression levels (again, in one of the nodes examined per patient) in LNs from all the VC patients enrolled in the study was arbitrarily chosen as a cut-off value for patient stratification. $P<0.05$ was considered significant.

\section{Results}

\section{Identification of expressed genes associated with LN} metastasis

The microarray data from two LN samples, one $\mathrm{LN}(+)$ and one $\mathrm{LN}(-)$, from one patient (case No. 15) with a rapid disease progression, were analyzed using pumaDE function from the PUMA package 1.8.1 [13]. The filtered dataset comprised 907 probe-sets with $P$ value below 0.05 (five percent Benjamini-Hochberg false discovery rate) differentially expressed in these two LN samples. This list included only up-regulated genes in $\mathrm{LN}(+)$ samples as no genes were found to be reduced in $\mathrm{LNs}(+)$ compared to $\mathrm{LNs}(-)$.

To evaluate which biological processes are represented within the obtained probe set list, the differentially expressed genes were annotated with the Gene Ontology (GO) terms. The most significantly over-represented ontology classes for the genes differentiating between $\mathrm{LN}(+)$ and $\mathrm{LN}(-)$ tissue are given in Table 2. The most up-regulated genes include those coding for epidermal molecules as well as molecules associated with cell adhesion, locomotory behaviour and inflammatory response.

Table 2 Significant Gene Ontology categories overrepresented among differentially expressed genes

\begin{tabular}{lllll}
\hline GO category & GO term & Exp. No. & $\boldsymbol{P}$ & $\boldsymbol{P a}$ \\
\hline GO:0007155 & cell adhesion & 28.3 & $1,52 \mathrm{E}-09$ & $2,07 \mathrm{E}-06$ \\
G0:0008544 & epidermis development & 2.7 & $6,70 \mathrm{E}-09$ & $4,54 \mathrm{E}-06$ \\
G0:0032502 & developmental process & 22.2 & $1,85 \mathrm{E}-06$ & 0,000837 \\
G0:0007275 & multicellular organismal & 80.8 & $2,74 \mathrm{E}-06$ & 0,000928 \\
& development & & & \\
G0:0048730 & epidermis morphogenesis & 1.5 & $1,15 \mathrm{E}-05$ & 0,00311 \\
GO:0030216 & keratinocyte differentiation & 1.0 & $3,35 \mathrm{E}-05$ & 0,006311 \\
GO:0007626 & locomotory behavior & 7.2 & $3,45 \mathrm{E}-05$ & 0,006311 \\
G0:0006954 & inflammatory response & 11.6 & $3,72 \mathrm{E}-05$ & 0,006311 \\
\hline
\end{tabular}

Abbreviations: GO - Gene Ontology; Exp. No. - the expected number of differentially expressed genes (probesets) to be found among genes annotated to each GO term; $P$ - $P$ value; $P a$ - adjusted $P$ value.

\section{Gene selection for validation}

Based on the results of microarray analysis by the pumaDE function of PUMA package 1.8.1, we aimed to select genes with the highest fold-change of expression between $\mathrm{LN}(+)$ and $\mathrm{LN}(-)$ obtained from the patient No. 15 , and lowest significant adjusted $P$ values, to be assessed by the quantitative PCR. Genes with over twofold differences in expression levels were selected from the list and further categorized into different functions and cellular processes. The genes significantly differentially expressed (at $P$ value below 0.01 ) in the analyzed LN obtained from patient No. 15 were represented by 408 probe sets (Additional file: 1 Table S1). The genes selected were those with the highest fold-change values, represented by specific probe sets (named with the suffix '_at'), and those belonging to different GO categories. The group of genes of interest was further reduced to those which also proved to differentiate $\mathrm{LNs}(+)$ from LNs(-) in the PUMA analysis of microarray data of the three additional pairs of nodes from three consecutive patients (No. 21, 46 and 61). A list of the genes differentially expressed in $\mathrm{LN}(+)$ and $\mathrm{LN}(-)$ samples obtained from these four $\mathrm{VC}$ patients is presented in the Additional file: 2 Table S2.

Next, only the genes up-regulated in the four LNs(+) obtained from the four VC patients were analyzed in Genevestigator V3 system. Genevestigator allowed to validate their increased expression in vulva, as this repository contains high quality microarray expression data from experiments performed on 27 non-cancer vulvar tissue samples (including nine specimens of vulvar intraepithelial neoplasia, VIN). The genes that showed high signal intensities in these 27 microarray data sets were selected. The probe sets were chosen on the basis of the highest \% Present" value generated in the Genevestigator. These values represent a fraction of arrays in which the signal for a given probe set is above the background. Finally, seven genes were selected from the microarray studies: TP53 apoptosis effector - PERP, S100 calcium binding protein A8 - S100A8, fatty acid binding protein 5 (psoriasis-associated) - FABP5, stratifin - SFN, carbonic anhydrase 12 - CA12, junction plakoglobin JUP and cystatin A - CSTA. Five out of the seven selected genes, namely, S100A8, FABP5, SFN, JUP and CSTA, have been described by Hsiao et al. [15] as "vulva-selective".

\section{Validation of gene expression levels by real-time RT-PCR}

To investigate the reliability of the cDNA microarray results and to check if our gene selection was correct, the expression levels of seven genes, PERP, S100A8, FABP5, SFN, CA12, JUP and CSTA, were measured by the qRT-PCR in $22 \mathrm{LN}(+)$ and $49 \mathrm{LN}(-)$ samples. 


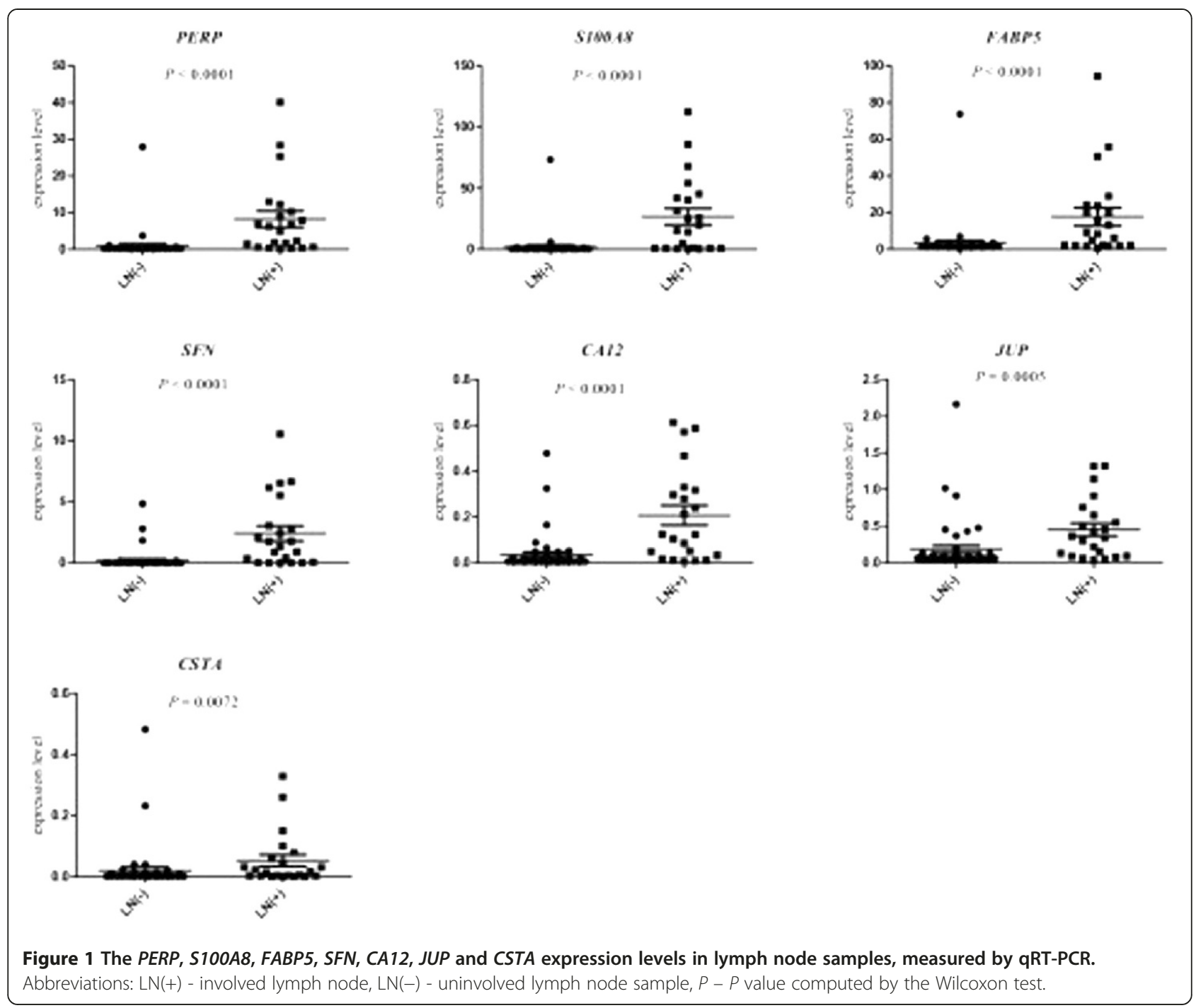

We confirmed the significant differences in the expression levels between uninvolved and involved (as assessed by routine histopathological analysis) of the all the seven genes in question (see Figure 1). As shown in Additional file: 3 Table S3, the expression levels of all of the seven genes tested by the qRT-PCR, in agreement with the microarray data, was lower in $\mathrm{LN}(-)$ than in $\mathrm{LN}(+)$.

\section{Correlations between gene expression levels and time to groin recurrence in VC patients}

Subsequently, we examined a correlation between the expression levels of the seven selected genes and time to groin recurrence in VC patients using Cox's proportional hazard analysis. The highest expression value of a given gene of all obtained in different LN samples of the same patient was taken into account. Three genes, SFN, CA12 and JUP, significantly correlated with TTR. High expression levels of the set of the four remaining genes in LNs were also associated with shorter TTR, but the trend did not reach statistical significance (Table 3).

Finally, patients were stratified by the arbitrarily chosen cut-off values, i.e. the medians of maximum

Table 3 Impact of gene expression levels in LN samples on TTR and its significance

\begin{tabular}{lll}
\hline Transcript & Coef. & $\boldsymbol{P}$ \\
\hline SFN & 0.3119 & 0.01 \\
CA12 & 3.8410 & 0.01 \\
JUP & 1.2405 & 0.01 \\
CSTA & 2.9463 & 0.17 \\
S100A8 & 0.0075 & 0.39 \\
FABP5 & 0.0061 & 0.59 \\
PERP & 0.0108 & 0.69 \\
\hline
\end{tabular}

Abbreviations: $T T R$ - time to groin recurrence, Coef. - Cox-model coefficient of modification of recurrence hazard by a given variable (i.e. gene expression); $P$ - $P$ value computed using Cox's proportional hazard analysis. 
gene expression levels in LNs from all the VC patients enrolled in the study (again, one node with the highest gene expression was taken into account per patient). Kaplan-Meier analysis was used for comparison of TTR between the groups of patients stratified according to gene expression status, i.e. high (above the cut-off value) vs low gene expression status (below the cut-off value) and irrespective of the histopathological evaluation of their LNs status. Initially, Kaplan-Meier estimates of TTR were used for the evaluation of the prognostic value of the SFN, CA12 and JUP gene expression, the genes whose expression was found to correlate significantly with TTR in above-mentioned COX-model analysis. Further, an analogous Kaplan-Meier analysis of the remaining four genes revealed the prognostic value of the expression level of CSTA gene. The Kaplan-Meier plots show the association of TTR with the LN expression levels of SFN, CA12, JUP and CSTA in VC patients, i.e. the expression levels of these genes predicted TTR (see Figure 2). The results of comparison of the KaplanMeier estimates for TTR depending on the expression level of SFN, CA12, JUP and CSTA genes, together with the cut-off values used for this analysis, are presented in Table 4. The differences in TTR between the groups of VC patients stratified by PERP, S100A8 and $F A B P$ gene expression levels were not significant (Kaplan-Meier curves not shown).

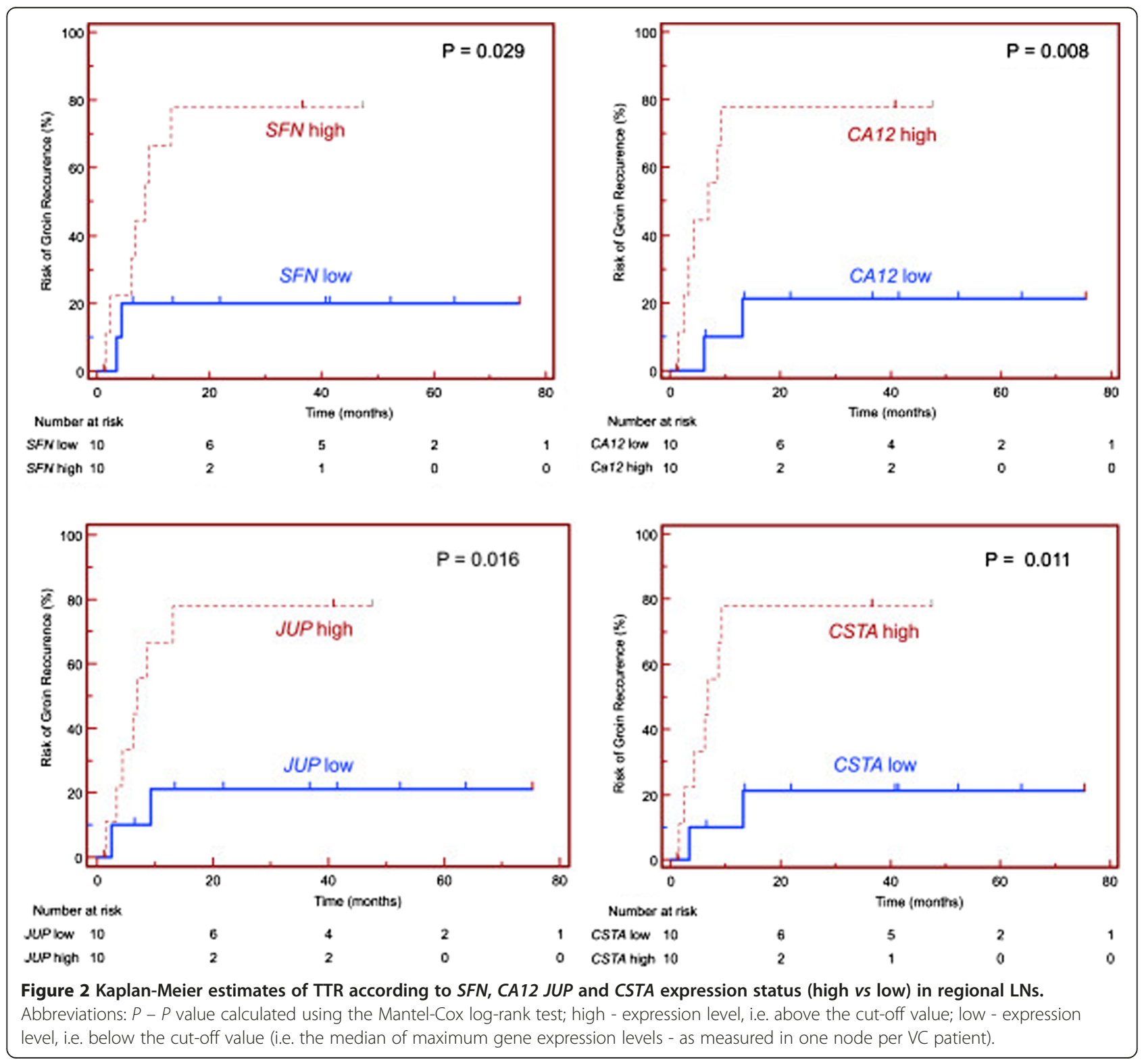


Table 4 The results of the comparison of Kaplan-Meier estimates for TTR for VC patients according to their LN gene expression levels

\begin{tabular}{|c|c|c|c|c|c|}
\hline \multirow[t]{2}{*}{ Transcript } & & \multicolumn{2}{|c|}{ TTR for patients with high expression level } & \multirow{2}{*}{$\begin{array}{l}\text { TTR for patients with } \\
\text { low expression level } \\
\text { Median TTR (months) }\end{array}$} & \multirow[t]{2}{*}{$P$} \\
\hline & Cut-off Value & Median TTR (months) & $\mathrm{HR} ; \mathrm{Cl}$ & & \\
\hline SFN & 0.4815 & 8.7 & $0.21 ; 95 \% \mathrm{Cl}, 0.06-0.86$ & not reached & 0.029 \\
\hline CA12 & 0.23 & 6.9 & $0.16 ; 95 \% \mathrm{Cl}, 0.04-0.61$ & not reached & 0.008 \\
\hline JUP & 0.4815 & 6.89 & $0.18 ; 95 \% \mathrm{Cl}, 0.05-0.74$ & not reached & 0.016 \\
\hline CSTA & 0.03 & 6.89 & $0.17 ; 95 \% \mathrm{Cl}, 0.04-0.66$ & not reached & 0.011 \\
\hline
\end{tabular}

Abbreviations: $T R R$ - time to groin recurrence; $H R$ - hazard ratio; $\mathrm{Cl}$ - confidence interval; Cut-off Value - the arbitrarily chosen cut-off for gene expression value used for patient stratification; $P-P$ value calculated with the use of the log-rank test.

\section{Discussion}

Lymph node status is the most important prognostic factor in patients with VC [16]. Routine pathological staging is limited to the microscopic evaluation of H\&E-stained LN sections. Unfortunately, small tumour foci may occasionally be missed by the pathologist in this examination [17]. As stated by Regauer [18], sentinel LNs of VC patients with even single tumour cells should be regarded as positive. Thus, to improve detection of LN metastases, pathological ultrastaging should ideally be performed $[19,20]$. This histological work-up of LNs involves serial sectioning and immunohistochemical analysis; the procedure is labour-intensive and time-consuming. Real-time RT-PCR technology is more sensitive, as it allows to detect a very small number of cells in larger volumes of previously pulverized (or homogenized) tissues. However, this method carries some disadvantages, for example it makes morphologic evaluation of the analyzed samples impossible. Therefore, a careful marker selection for RT-PCR analysis is a fundamental issue.

Since there are no molecular markers for diagnosing $\mathrm{VC}$ dissemination, we aimed to identify the potential mRNA markers of $\mathrm{VC}$ dissemination into LNs, and to verify their prognostic value by correlating their levels with time to groin recurrence. We used oligonucleotide microarrays which measure the expression level of over 47,000 transcripts and variants of human genes.

At first, the PUMA package, enabling a comparison between small-sample gene expression data [21] was employed, to analyze two samples obtained from one patient, who underwent a rapid progression of the disease during the follow-up time, with local recurrence, and groin recurrence in the same groin where the $\mathrm{LN}(+)$, and died due to cancer progression. The PUMA analysis produced a list of genes differentially expressed in $\mathrm{LN}(+)$ and $\mathrm{LN}(-)$. The most significantly over-represented gene ontology (GO) classes in the list included epidermal molecules. Thus, some of the differentially expressed genes are those specifically expressed in the primary tumour site. This finding testifies the methodology used for the comparison of the single microarray experiments.
Similar results were obtained for the three additional pairs of LNs obtained from three patients.

Interestingly, gene expression signature distinguishing between the four pairs of histologically positive and negative LNs comprised no genes down-regulated in the metastatic LNs of the same patients. A possible explanation of this observation is that only transcripts that were highly up-regulated in the metastatic cells could be distinguished from the background of the numerous non-cancer cells as an "added value" while downregulated transcripts, i.e. transcripts' deprivation, would not be noticed in this background environment.

The consecutive steps of narrowing-down of the list of the differentially expressed in the four LNs obtained from the four $\mathrm{VC}$ patients genes led us to the choice of seven genes, namely PERP, S100A8, FABP5, SFN, CA12, JUP and CSTA, to be validated by the real time RT-PCR. Gene expression data of 27 non-cancer vulvar tissue samples deposited in the Genevestigator V3 system $[22,23]$ have shown that these seven genes are regularly up-regulated in vulvar tissue. In addition, Hsiao et al. [15], who created a compendium of tissueselective genes based on microarray data, described five of these genes as "vulva-selective." This strongly supports tissue specificity of the selected genes for the primary tumour site.

To our knowledge, this is the first time that these genes have been linked to VC dissemination. PERP, as a component of intercellular desmosome junctions, plays a role in epithelial integrity and cell-cell adhesion [24] and constitutes a proapoptotic transcriptional target of TP53 [25]. PERP-deficiency promotes cancer by enhancing cell survival, desmosome loss, and inflammation [26]. S100 calcium binding protein A8, S100A8, belongs to S100 proteins, a family of EF-hand signalling proteins [27]. The complex of S100A8 and S100A9 called calprotectin induces a proinflammatory and thrombogenic response, and is involved in danger signalling; what is more, its stimulation results in a loss of cell-cell contacts [28,29]. S100A8/S100A9 expression is increased in patients with various tumours, being involved in invasion and migration processes [30,31]. S100A8/9 expression is minimal in 
normal epidermis and is elevated in skin diseases [32]. However, Dell'oste et al. [33] showed that in HPVimmortalized keratinocytes S100A8/9 expression was downregulated. Fatty acid binding protein 5 (psoriasisassociated, FABP5), found in epidermal cells, was first identified to be up-regulated in psoriasis keratinocytes [34]. In cancer cells, FABP5 increases cell proliferation and invasiveness, as recently demonstrated in oral squamous cell carcinoma [35] where its expression may be HPV-related [36]. In non-cancer keratinocytes FABP5 elevation may be necessary for the activation of cell motility during epidermal wound healing [37]. Stratifin, SFN (143-3 sigma), plays a role in various cellular processes being the most cancer-associated 14-3-3 isoform [38]. 14-3-3 sigma expression is lost in numerous tumours [38], including VC [39], while its increased expression could be associated with a loss of TP53 function [40,41]. However, Wang et al. [42] found high levels of SFN detected immunohistochemically in over $70 \%$ of analyzed VC tumors, significantly correlating to large tumor diameter and deep invasion. Importantly, 14-3-3 sigma protein is present in various normal epithelia and absent in LNs [43,44], and lymphocytes may express its mRNA at relatively low levels [45]. Carbonic anhydrase XII is one of the tumourassociated carbonic anhydrases. The enzyme is overexpressed under hypoxic conditions and constitutes a possible target for anticancer therapy [46,47]. Junction plakoglobin, JUP, a member of the catenin family, is present both in desmosomes and in intermediate junctions [48]. The majority of studies suggest that plakoglobin has a tumour suppressor role [49]. Cystatin A (stefin A), CSTA, functions as a cysteine protease inhibitor and plays a role in epidermal development and maintenance. Serum level of CSTA has been proposed as a tool predicting nodal stage and poor prognosis in nasopharyngeal carcinoma [50].

The comparison of $\mathrm{LNs}(+)$ with $\mathrm{LNs}(-)$ confirmed that $\mathrm{LNs}(+)$ express significantly more transcripts of PERP, S100A8, FABP5, SFN, CA12, JUP and CSTA. The results of $\mathrm{PCR}$ analysis showed particularly increased expression of S100A8 and SFN in the metastatic LNs, where there was over 10-fold change of the mean expression level. Higher expression of PERP, FABP5, $C A 12$, JUP and CSTA were also found, but the differences were lower.

The significance of gene expression levels in LN samples for time to groin recurrence (TTR) was statistically analyzed using Cox's proportional hazard model. A coefficient computed by this method for each variable expression of "predictor" genes indicates the direction and degree of flexing that the predictor has on the TTR curve. A positive value of coefficients indicated that larger values of the expression were associated with greater groin recurrence rates. Two genes, namely $S F N$ and $C A 12$, were found significantly predictive of such recurrence. High expression levels of the other genes of the set of five in LNs were also associated with shorter TTRs, but the trend did not reach statistical significance.

The log-rank test used for testing significance of the TTR functions in Kaplan-Meier analysis yielded significant $P$ values for separating the two groups of $\mathrm{VC}$ patients with different TTR according to their LN gene expression levels of SFN, CA12, JUP and CSTA. Patients with low expression of these genes had a superior TTR values of not reached versus 6.9 to 8.7 months.

It is worth noting that our study had some important limitations. Firstly, only seven of the most differentially expressed genes in the microarray experiment were analyzed by the qRT-PCR. Notwithstanding, the remaining genes (see Additional file: 2 Table S2) are candidates for validation in further studies. Secondly, LN assessment was based on routine pathological evaluation with $H \& E$ staining, while the state-of-the-art would be to perform ultrastaging on the excised LNs. Lastly, Kaplan-Meier analysis of TTR that was applied to SFN, CA12, JUP and CSTA expression, should be considered as just an illustration of potential clinical use of the identified marker genes. Future studies should include more patients to assure a better assessment of the novel markers' performance. Such studies should also provide better cut-off values for patients' stratification than the arbitrarily chosen median expression levels in LNs, and enable the ROC curve analysis. Importantly, our microarray data were obtained for HPV-negative patients in order to exclude the interference of the infection with the expression results and to focus on metastasis-associated genes' selection. However, patients with HPV infection should also be enrolled in future studies to assess the influence of HPV on the markers' performance.

Groin recurrences from VC are often fatal. Unfortunately, "the optimum mode of treatment and predictive factors for patients with groin recurrences are unknown" [51]. The size of LN metastases correlates with survival in patients with early [52] and advanced [53] stage VC. On the other hand, "inguinofemoral lymphadenectomy can be avoided when the sentinel node is negative for disease" [54]. However, although Oonk and colleagues [52] reported that the risk of non-sentinel LN involvement increases with size of sentinel LN metastases, they were unable to determine the cut-off size below which the risk of non-sentinel LN metastases would be inconsiderable. Therefore, the authors concluded that all patients with sentinel LN metastases - regardless of their size - should undergo additional groin treatment. The risk of additional metastases when only isolated tumour cells are present in the sentinel $\mathrm{LN}$ is $4 \%$ [55]. Still, approximately $12 \%$ of early-stage VC patients with a negative sentinel LN develop local recurrence" $[54,56]$. 
For the reasons discussed above, novel means to better stratify early-stage VC patients in order to optimize treatment modality, i.e. a tool to decide who should not undergo lymphadenectomy $v s$ who should receive additional treatment to the groin would be highly beneficial. Further validation of markers and development of molecular tests is indispensable for the reliable up- or down-staging of LNs. Our results may ideally be used to develop a test that could be used during surgery to decide whether to remove inguinal LNs, similarly to the RT-PCR based, FDA-approved GeneSearch ${ }^{\text {TM }}$ Breast Lymph Node (BLN) Assay (Veridex, LLC, Warren, NJ), used for the rapid intra-operative detection of sentinel LN metastases in breast cancer. Such tests may reduce the need for a second surgery for the axillary LN dissection [57-59]. As sentinel node procedure was confirmed to be safe in the early-stage VC patients [54], tests similar to GeneSearch ${ }^{\text {Ts }}$ should also be of clinical utility for $\mathrm{VC}$ patients.

\section{Conclusions}

To conclude, the performance of qRT-PCR assays employing the $\mathrm{LN}(+)$ marker genes that we have identified, PERP, S100A8, FABP5, SFN, CA12, JUP and CSTA, may provide a promising tool for intra-operative sentinel $\mathrm{LN}$ evaluation in VC patients. Moreover, all the above marker genes have a potential of prognostic biomarkers, however, before their incorporation into clinical setting further studies are necessary to confirm their prognostic value in the qRT-PCR assays.

\section{Additional files}

Additional file 1: Table S2. Genes differentially expressed in $L N(+)$ and $L N(-)$ sample obtained from VC patient No 15. Abbreviations: $P$ - $p$ value; $C P$ - Benjamini-Hochberg corrected $p$ value; FC - fold change of gene expression ratio in $\mathrm{LN}(+)$ and $\mathrm{LN}(-)$ sample; exp. - expression level.

Additional file 2: Table S3. Genes differentially expressed in the four $L N(+)$ and $L N(-)$ sample pairs obtained from VC patients No 15, 21, 46 and 61. Abbreviations: $P$ - $p$ value; NA - not applicable.

Additional file 3: Table S1. Mean levels of expression of PERP, S100A8, FABP5, SFN, CA12, JUP and CSTA in LN(+) and LN(-) samples, measured by qRT-PCR. Abbreviations: ME - mean expression level in all involved [LN $(+)]$ and uninvolved $[\mathrm{LN}(-)]$ lymph node samples included in the qRTPCR analysis.

\section{Competing interests}

The authors declare that they have no competing interests.

\footnotetext{
Acknowledgements

The authors are grateful to Drs. R. Nowak and M. Chechlinska for the critical reading of the manuscript. This work was supported by the research grants No. P05E 11624 and NN407 125937 from the Ministry of Science and Higher Education. K.G. is supported by the Ministry of Science and Higher Education grant No. NN518331736.

\section{Author details}

'Department of Molecular Biology, Maria Sklodowska-Curie Memorial Cancer Centre and Institute of Oncology, Roentgena, 5, Warsaw 02-781, Poland.
}

${ }^{2}$ Department of Surgery, Maria Sklodowska-Curie Memorial Cancer Centre and Institute of Oncology, Wawelska 15, Warsaw 00-973, Poland. ${ }^{3}$ Department of Oncological Genetics, Maria Sklodowska-Curie Memorial Cancer Centre and Institute of Oncology, Roentgena 5, Warsaw 02-781, Poland. ${ }^{4}$ Laboratory of Bioinformatics and Systems Biology, Maria Sklodowska-Curie Memorial Cancer Centre and Institute of Oncology, Roentgena 5, Warsaw 02-781, Poland. ${ }^{5}$ Department of Nuclear Medicine and Endocrine Oncology, Maria Sklodowska-Curie Memorial Cancer Center and Institute of Oncology, Wybrzeze Armii Krajowej 15, Gliwice 44-100, Poland. ${ }^{6}$ Department of Gynecological Oncology, Maria Sklodowska-Curie Memorial Cancer Centre and Institute of Oncology, Roentgena, 5, Warsaw 02-781, Poland.

\section{Conflicts of interest}

The authors report no potential conflicts of interest.

\section{Authors' contributions}

MK and JR designed and coordinated the study. MBidzinski, JAS and MJ participated in its coordination. MK wrote the manuscript. KG and MBujko performed the statistical analysis. MO-W and MK carried out the microarray and qRT-PCR experiments, respectively. All authors read and approved the final manuscript.

Received: 9 October 2011 Accepted: 6 June 2012

Published: 6 June 2012

\section{References}

1. In Cancer incidence in five continents vol. VIII. Edited by Parkin DM, Ferlay J, Teppo L, Thomas DB.: IARC Scientific Publications No. 155 IARC; 2002.

2. National Cancer Registry, available at: http://epid.coi.waw.pl/krn/.

3. Raspagliesi F, Hanozet F, Ditto A, Solima E, Zanaboni F, Vecchione F, Kusamura S: Clinical and pathological prognostic factors in squamous cell carcinoma of the vulva. Gynecol Oncol 2006, 102:333-337.

4. Selman TJ, Luesley DM, Acheson N, Khan KS, Mann CH: A systematic review of the accuracy of diagnostic tests for inguinal lymph node status in vulvar cancer. Gynecol Oncol 2005, 99:206-214.

5. Hacker NF, Berek JS, Lagasse LD, Leuchter RS, Moore JG: Management of regional lymph nodes and their prognostic influence in vulvar cancer. Obstet Gynecol 1983, 61:408-412.

6. Lugo TG, Braun S, Cote RJ, Pantel K, Rusch V: Detection and measurement of occult disease for the prognosis of solid tumors. J Clin Oncol 2003, 21:2609-2615.

7. Rutgers EJ: Sentinel node biopsy: interpretation and management of patients with immunohistochemistry-positive sentinel nodes and those with micrometastases. J Clin Oncol 2008, 26:698-702.

8. Knopp S, Trope C, Nesland JM, Holm R: A review of molecular pathological markers in vulvar carcinoma: lack of application in clinical practice. J Clin Pathol 2009, 62:212-218.

9. Kowalewska M, Radziszewski J, Kulik J, Barathova M, Nasierowska-Guttmajer A, Bidzinski M, Pastorek J, Pastorekova S, Siedlecki JA: Detection of carbonic anhydrase 9-expressing tumor cells in the lymph nodes of vulvar carcinoma patients by RT-PCR. Int J Cancer 2005, 116:957-962.

10. Kowalewska M, Szkoda MT, Radziszewski J, Ptaszynski K, Bidzinski M, Siedlecki JA: The frequency of human papillomavirus infection in polish patients with vulvar squamous cell carcinoma. Int J Gynecol Cancer 2010, 20:434-437.

11. Ihaka R, Gentleman R: R: a language for data analysis and graphics. Journal of Computational and Graphical Statistics 1996, 5:299-314.

12. Benjamini $Y$, Hochberg $Y$ : Controlling the false discovery rate: a practical and powerful approach to multiple testing. Journal of the Royal Statistical Society Series B 1995, 57:289-300.

13. Liu X, Milo M, Lawrence ND, Rattray M: A tractable probabilistic model for Affymetrix probe-level analysis across multiple chips. Bioinformatics 2005, 21:3637-3644.

14. Hruz T, Laule O, Szabo G, Wessendorp F, Bleuler S, Oertle L, Widmayer P, Gruissem W, Zimmermann P: Genevestigator v3: a reference expression database for the meta-analysis of transcriptomes. Adv Bioinformatics 2008, 2008:420747.

15. Hsiao LL, Dangond F, Yoshida T, Hong R, Jensen RV, Misra J, Dillon W, Lee KF, Clark KE, Haverty $P$, et al: A compendium of gene expression in normal human tissues. Physiol Genomics 2001, 7:97-104. 
16. Hacker NF: Revised FIGO staging for carcinoma of the vulva. Int J Gynaecol Obstet 2009, 105:105-106.

17. Knopp S, Holm R, Trope C, Nesland JM: Occult lymph node metastases in early stage vulvar carcinoma patients. Gynecol Oncol 2005, 99:383-387.

18. Regauer S: Histopathological work-up and interpretation of sentinel lymph nodes removed for vulvar squamous cell carcinoma. Histopathology 2009, 55:174-181.

19. Gietema HA, Vuylsteke RJ, de Jonge IA, van Leeuwen PA, Molenkamp BG, van der Sijp JR, Meijer S, van Diest PJ: Sentinel lymph node investigation in melanoma: detailed analysis of the yield from step sectioning and immunohistochemistry. J Clin Pathol 2004, 57:618-620.

20. Weaver DL, Le UP, Dupuis SL, Weaver KA, Harlow SP, Ashikaga T, Krag DN: Metastasis detection in sentinel lymph nodes: comparison of a limited widely spaced (NSABP protocol B-32) and a comprehensive narrowly spaced paraffin block sectioning strategy. Am J Surg Pathol 2009, 33:1583-1589

21. Pearson RD, Liu X, Sanguinetti G, Milo M, Lawrence ND, Rattray M: puma: a Bioconductor package for propagating uncertainty in microarray analysis. BMC Bioinformatics 2009, 10:211.

22. Santegoets LA, Seters M, Helmerhorst TJ, Heijmans-Antonissen C, HanifiMoghaddam P, Ewing PC, van ljcken WF, van der Spek PJ, van der Meijden WI, Blok L: HPV related VIN: highly proliferative and diminished responsiveness to extracellular signals. Int J Cancer 2007, 121:759-766.

23. http://www.ncbi.n/m.nih.gov/projects/geo/query/acc.cgi?acc=GSE7307.

24. Ihrie RA, Attardi LD: A new Perp in the lineup: linking p63 and desmosomal adhesion. Cell Cycle 2005, 4:873-876.

25. Reczek EE, Flores ER, Tsay AS, Attardi LD, Jacks T: Multiple response elements and differential p53 binding control Perp expression during apoptosis. Mol Cancer Res 2003, 1:1048-1057.

26. Beaudry VG, Jiang D, Dusek RL, Park EJ, Knezevich S, Ridd K, Vogel H, Bastian BC, Attardi LD: Loss of the p53/p63 regulated desmosomal protein Perp promotes tumorigenesis. PLoS Genet 2010, 6:e1001168

27. Santamaria-Kisiel L, Rintala-Dempsey AC, Shaw GS: Calcium-dependent and -independent interactions of the S100 protein family. Biochem J 2006 396:201-214.

28. Ehrchen JM, Sunderkotter C, Foell D, Vogl T, Roth J: The endogenous Tolllike receptor 4 agonist S100A8/S100A9 (calprotectin) as innate amplifier of infection, autoimmunity, and cancer. J Leukoc Biol 2009, 86:557-566.

29. Viemann D, Strey A, Janning A, Jurk K, Klimmek K, Vogl T, Hirono K, Ichida F, Foell D, Kehrel B, et al: Myeloid-related proteins 8 and 14 induce a specific inflammatory response in human microvascular endothelial cells. Blood 2005, 105:2955-2962

30. Gebhardt C, Nemeth J, Angel P, Hess J: S100A8 and S100A9 in inflammation and cancer. Biochem Pharmacol 2006, 72:1622-1631.

31. Moon A, Yong HY, Song Jl, Cukovic D, Salagrama S, Kaplan D, Putt D, Kim H, Dombkowski A, Kim HR: Global gene expression profiling unveils S100A8/ A9 as candidate markers in $\mathrm{H}$-ras-mediated human breast epithelial cell invasion. Mol Cancer Res 2008, 6:1544-1553.

32. Eckert RL, Broome AM, Ruse M, Robinson N, Ryan D, Lee K: S100 proteins in the epidermis. J Invest Dermatol 2004, 123:23-33.

33. Dell'oste V, Azzimonti B, Mondini M, De Andrea M, Borgogna C, Mesturini R, Accardi R, Tommasino M, Landolfo S, Dianzani U, Gariglio M: Altered expression of UVB-induced cytokines in human papillomavirusimmortalized epithelial cells. J Gen Virol 2008, 89:2461-2466.

34. Madsen P, Rasmussen HH, Leffers H, Honore B, Celis JE: Molecular cloning and expression of a novel keratinocyte protein (psoriasis-associated fatty acid-binding protein [PA-FABP]) that is highly up-regulated in psoriatic skin and that shares similarity to fatty acid-binding proteins. J Invest Dermatol 1992, 99:299-305.

35. Fang LY, Wong TY, Chiang WF, Chen YL: Fatty-acid-binding protein 5 promotes cell proliferation and invasion in oral squamous cell carcinoma. J Oral Pathol Med 2010, 39:342-348.

36. Melle C, Ernst G, Winkler R, Schimmel B, Klussmann JP, Wittekindt C, GuntinasLichius $\mathrm{O}$, von Eggeling F: Proteomic analysis of human papillomavirusrelated oral squamous cell carcinoma: identification of thioredoxin and epidermal-fatty acid binding protein as upregulated protein markers in microdissected tumor tissue. Proteomics 2009, 9:2193-2201.

37. Kusakari Y, Ogawa E, Owada Y, Kitanaka N, Watanabe H, Kimura M, Tagami $\mathrm{H}$, Kondo H, Aiba S, Okuyama R: Decreased keratinocyte motility in skin wound on mice lacking the epidermal fatty acid binding protein gene. Mol Cell Biochem 2006, 284:183-188.
38. Mhawech P: 14-3-3 proteins-an update. Cell Res 2005, 15:228-236

39. Gasco M, Sullivan A, Repellin C, Brooks L, Farrell PJ, Tidy JA, Dunne B, Gusterson B, Evans DJ, Crook T: Coincident inactivation of 14-3-3sigma and p16INK4a is an early event in vulval squamous neoplasia. Oncogene 2002, 21:1876-1881.

40. Hermeking $H$, Lengauer C, Polyak K, He TC, Zhang L, Thiagalingam S, Kinzle KW, Vogelstein B: 14-3-3 sigma is a p53-regulated inhibitor of G2/M progression. Mol Cell 1997, 1:3-11.

41. Lee MH, Lozano G: Regulation of the p53-MDM2 pathway by 14-3-3 sigma and other proteins. Semin Cancer Biol 2006, 16:225-234.

42. Wang Z, Trope CG, Suo Z, Troen G, Yang G, Nesland JM, Holm R: The clinicopathological and prognostic impact of 14-3-3 sigma expression on vulvar squamous cell carcinomas. BMC Cancer 2008, 8:308.

43. Dellambra E, Golisano O, Bondanza S, Siviero E, Lacal P, Molinari M, D'Atri S, De Luca M: Downregulation of 14-3-3sigma prevents clonal evolution and leads to immortalization of primary human keratinocytes. J Cell Biol 2000, 149:1117-1130

44. Nakajima T, Shimooka H, Weixa P, Segawa A, Motegi A, Jian Z, Masuda N, Ide M, Sano T, Oyama T, et al: Immunohistochemical demonstration of 14-3-3 sigma protein in normal human tissues and lung cancers, and the preponderance of its strong expression in epithelial cells of squamous cell lineage. Pathol Int 2003, 53:353-360.

45. Bhatia K, Siraj AK, Hussain A, Bu R, Gutierrez Ml: The tumor suppressor gene 14-3-3 sigma is commonly methylated in normal and malignant lymphoid cells. Cancer Epidemiol Biomarkers Prev 2003, 12:165-169.

46. Pastorekova S, Zatovicova M, Pastorek J: Cancer-associated carbonic anhydrases and their inhibition. Curr Pharm Des 2008, 14:685-698.

47. Brzozowski Z, Slawinski J, Innocenti A, Supuran CT: Carbonic anhydrase inhibitors. Regioselective synthesis of novel 1-substituted 1,4-dihydro-4oxo-3-pyridinesulfonamides and their inhibition of the human cytosolic isozymes I and II and transmembrane cancer-associated isozymes IX and XII. Eur J Med Chem 2010, 45:3656-3661.

48. Delva E, Tucker DK, Kowalczyk AP: The desmosome. Cold Spring Harb Perspect Biol 2009, 1:a002543.

49. Chidgey M, Dawson C: Desmosomes: a role in cancer? Br J Cancer 2007 96:1783-1787

50. Chang KP, Wu CC, Chen HC, Chen SJ, Peng PH, Tsang NM, Lee LY, Liu SC, Liang $Y$, Lee $Y S$, et al: Identification of candidate nasopharyngeal carcinoma serum biomarkers by cancer cell secretome and tissue transcriptome analysis: potential usage of cystatin A for predicting nodal stage and poor prognosis. Proteomics 2010, 10:2644-2660.

51. Cormio G, Loizzi V, Carriero C, Cazzolla A, Putignano G, Selvaggi L: Groin recurrence in carcinoma of the vulva: management and outcome. Eur J Cancer Care (Engl) 2010, 19:302-307.

52. Oonk MH, van Hemel BM, Hollema H, de Hullu JA, Ansink AC, Vergote I, Verheijen RH, Maggioni A, Gaarenstroom KN, Baldwin PJ, et al: Size of sentinelnode metastasis and chances of non-sentinel-node involvement and survival in early stage vulvar cancer: results from GROINSS- $V$, a multicentre observational study. Lancet Oncol 2010, 11:646-652

53. Origoni M, Sideri M, Garsia S, Carinelli SG, Ferrari AG: Prognostic value of pathological patterns of lymph node positivity in squamous cell carcinoma of the vulva stage III and IVA FIGO. Gynecol Oncol 1992, 45:313-316.

54. Van der Zee AG, Oonk MH, De Hullu JA, Ansink AC, Vergote I, Verheijen RH, Maggioni A, Gaarenstroom KN, Baldwin PJ, Van Dorst EB, et al: Sentinel node dissection is safe in the treatment of early-stage vulvar cancer. J Clin Oncol 2008, 26:884-889.

55. Oonk MH, de Hullu JA, van der Zee AG: Current controversies in the management of patients with early-stage vulvar cancer. Curr Opin Oncol 2010, 22:481-486.

56. Tantipalakorn C, Robertson G, Marsden DE, Gebski V, Hacker NF: Outcome and patterns of recurrence for International Federation of Gynecology and Obstetrics (FIGO) stages I and II squamous cell vulvar cancer. Obstet Gynecol 2009, 113:895-901.

57. Julian TB, Blumencranz $P$, Deck K, Whitworth $P$, Berry DA, Berry SM, Rosenberg A, Chagpar AB, Reintgen D, Beitsch $P$, et al: Novel intraoperative molecular test for sentinel lymph node metastases in patients with early-stage breast cancer. J Clin Oncol 2008, 26:3338-3345.

58. Funasako $Y$, Uenosono $Y$, Hirata M, Arigami T, Yanagita S, Arima H, Ehi K, Kijima Y, Yoshinaka H, Natsugoe S: Utility of the GeneSearch breast lymph node assay for the rapid evaluation of sentinel lymph nodes in breast cancer. Cancer 2010, 116:4450-4455. 
59. Mansel RE, Goyal A, Douglas-Jones A, Woods V, Goyal S, Monypenny I, Sweetland H, Newcombe RG, Jasani B: Detection of breast cancer metastasis in sentinel lymph nodes using intra-operative real time GeneSearch BLN Assay in the operating room: results of the Cardiff study. Breast Cancer Res Treat 2009, 115:595-600.

doi:10.1186/1471-2407-12-223

Cite this article as: Kowalewska et al.: Estimation of groin recurrence risk in patients with squamous cell vulvar carcinoma by the assessment of marker gene expression in the lymph nodes. BMC Cancer 2012 12:223.

\section{Submit your next manuscript to BioMed Central and take full advantage of:}

- Convenient online submission

- Thorough peer review

- No space constraints or color figure charges

- Immediate publication on acceptance

- Inclusion in PubMed, CAS, Scopus and Google Scholar

- Research which is freely available for redistribution 